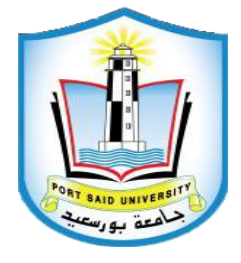

$$
\begin{aligned}
& \text { جامعة بورسعيد } \\
& \text { كلية التجارة } \\
& \text { قسم العلوم السباسبة والإدارة العامة }
\end{aligned}
$$

\title{
بمث بمنثان
}

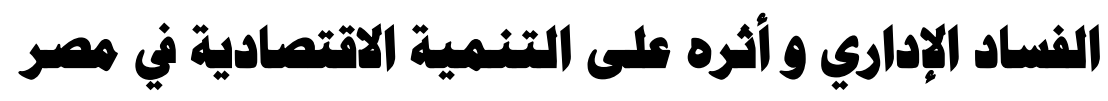

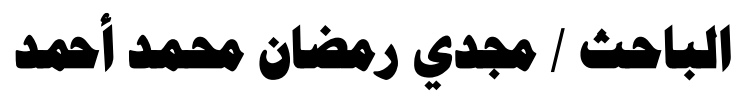

الأستاذ الدكتور

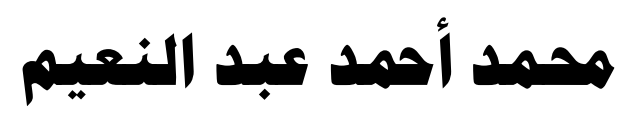

أستاذ القانون العام -عمبـ كلية الحقوق

جامعة بورسعيد
الأستاذة الاكتورة

\section{نtân}

أستاذ مساعد العلوم السياسبة

بكلية التجارة -جامعة بورسعيد 


\section{الإطار العام للبحث}

مقدمة:

تعتبر ظاهرة الفساد الإداري ظاهرة عالمية شديدة الانتشار ذات جذور عميقة تأخذ ابعادا واسعة تتداخل فيها عوامل مختلفة، لا يخلو مجتمع أو نظام سياسي منها .

ويشكل الفساد خطرا داهما يواجه الدول النامية والمتقدمة على حد سواء باعتباره معوقا رئيسيا لتحقيق التنمية المستدامة من خلال المساهمة فى ضعف النمو الاثتصادي وتكريس الاختلافات إلى تدنى كفاءه القطاع الحكومى وأدائه، وارتفاع حجم الاضرار بالمال العام.

رغم الجهود التي بذلت لمكافحة الفساد والحد من انتثاره إلا أنه في ازدياد على مر الايام، ولعل السبب في ذلك يعود إلى غياب الرقابة الأتية لاى الافراد من جهة وصعوية الكثف عنه من جهة أخرى، لان كل مساهم في عملية الفساد يحاول إخفاء معالمه خثية من أن يقع تحت طائلة العقاب أو رغبه في إنجاز المصلحة التي ينشدها. أولا :أهداف البحث:

يهاف هذا البحث الى دراسة أثثار الفساد الإداري وذلك من خلال تسليط الضوء على مفهوم الفساد ، اثاره الاقتصادية ، الاجتماعية ، على حجم وطبيعة الايرادات الحكومية ، على النواحي السياسية ثانبا:اهمبه البحث :

تأتى أهمية البحث في تسليط الضوء على اثار الفساد الإداري في مصر وكيفية مواجهته والحد منه وأحكام الرقابة والسيطرة عليه . 
ثالثا: أهداف البحث:

تحديد مفهوم الفساد الادارى ، اثار الفساد فى المجال الاقتصادى ، وعلى حجم وطبيعه الايرادات الحكومية ، على النواحى الاجتماعية .

لإيعا: فروض البحث:

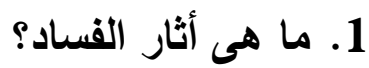

2. ما هى أثثار الفساد على الناحيه الاقتصاديه ؟

3. ما هى أثار الفساد على النواحى السياسية ؟

4. ما هى أثثار الفساد على النواحى الاجتماعية ؟

خامسا: منهج البحث:

المنهج الوصفى التحليلي:

يعتمد هذا البحث على المنهج الوصفي التحليلي في دراسة ظاهرة الفساد الإداري في مصر، اثاره، أسبابه، أنماطه بغرض وضع روئه مستقبليه لمكافحة الفساد في مصر والحد منه. سادسا: الارراسات السابقه: ويضم الاراسات التي تناولت الفساد الإداري:

1. دراسة :د. عطية حسين أفندي: مفاهيم هامة في الممارسات الادارية "الفساد الإداري " كلية الاقتصاد والعلوم السياسية ـ جامعه القاهرة . 2001. التي سعت الى دراسة تعريف الفساد الإداري، اسباب الفساد، أثثار الفساد، الاجراءات المؤسسية لمقاومه الفساد الحكومي.

2.دراسة: عماد الدين إسماعيل ظاهرة الفساد الإداري في الاجهزة الحكومية بالتركيز على الرشوة . كليه الاقتصاد والعلوم السياسية ـ جامعه القاهزة 2003. 
التي سعت اللى دراسة مفهوم الاخلاقيات في الادارة العامة، مفهوم الرشوة، طرق مكافحه الرشوة، اسبابها، مقاومه الرشوة، القاء الضوء على ظاهرة الفساد الإداري في الاجهزة الحكومية، توصيف ظاهرة الرشوة في مصر وإببابها ونتائجها السلبية.

3.دراسة: د عصام عبد الفتاح مطر". الفساد الإداري ـ ماهيته، اسبابه، مظاهره ـ الوثائق العالمية والوطنية المعنية بمكافته ـ دور الهيئات الحكومية وغير الحكومية في مواجهه الفساد دار الجامعة الجديدة، الإسكندرية 2011.

التي سعت الى دراسة مفهوم الفساد، تعريف الفساد، الابعاد التاريخية للفساد الإداري، اسباب الفساد، أثكال الفساد، دور الهيئات والمؤسسات الحكومية وغير الحكومية في محاريه الفساد. سابعا: أقسام البحث : في هذا المبحث النقاط التالبة : 1. التعرف على ماهية الفساد. 2. أثثار الفساد على المجال الاقتصادى . 3. أثار الفساد على حجم وطبيعه الايرادات الحكومية . 4. أثار الفساد على النواحى الاجتماعية . 5. أثار الفساد على النواحى السياسية .

\section{أولا : مفهوم الفساد الاداري}

الفساد: يعرف لغويا بأن الخراب والتلف والانحلال والتعفن. يشتق لفظ الفساد لغة (corruption) من الفعل اللاتيني ( Rump ere) أي يكسر , وهو ما يعني أن قاعدة سلوك معينة قد كسرت ولذلك يعرف قاموس ويفسر كلمة الفساد بأنها انحراف 
الثيء أي السلوك عن الأصل أو عن حالة نقائه الأصلية، خروج الثئون الاعتدال سواء كان الخروج قليلا أو كثيرا, يقال فسد الشيء بمعنى أنه لم يعد صالحا، وفسدت الأمور.

الفساد الإداري يتعلق بمظاهر الفساد والانحراف الإداري أو الوظيفي من خلال المنظمة والتي تصدر من الموظف العام اثثاء تأدية العمل بمخالفه التشريع القانوني وضوابط القيم الفردية، أي استغلال موظفي الدولة لمواقعهم وصلاحياتهم للحصول على مكاسب ومنافع بطرق غير شرعيه . (1)

الفساد يرتبط باستعداد الموظفين الرسميين لقبول الرشاوى ففي الحياه اليومية عاده ما يستخلم مصطلح الفساد للإثشارة الى سوء استعمال الإداري او السياسي للسلطة المرتبطة بالمنصب الذى يشظله ليحصل على نفسه على دخل اعلى من الدخل الرسمي المرتبط بهذا المنصب. (2)

\section{تعريف الفساد في علم الادارة:}

هو تدنى وانحطاط مستوى الادارة وأخر هو استغلال موقع معين لأغراض شخصيه ومنفعة شخصيه على حساب المنفعة العامة، وإساءة استعمال الوظيفة والتسيب فيها والاغفال عنها والتلكؤ والاهمال في تأديتها للكسب الخاص وتقديم المنفعة الخاصة على العامة وهو سوء استخدام الفرد للسلطة الموكلة اليه لأغراض الريح الخاص والمنفعة غير المشروعة (3). تعريف موسوعة العلوم الاجتماعية (الفساد هو سوء استخدام النفوذ العام لتحقيق أرياح خاصة) كما عرفته (هو خروج عن القانون والنظام العام وعدم الالتزام بهما من أجل تحقيق مصالح سياسية واقتصاديه للفرد أو لجماعة معينة).

(1) عطية حسين أفندي ـ الادارة العامة ـ إطار نظري ـ مداخل للنطوير ـ وقضايا هامة في الممارسة ـ دار النهضة العربية ـ كليه

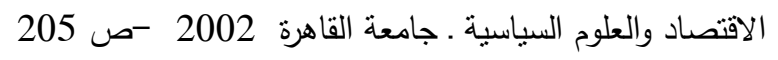

(2)W.F.Wertheim, Sociological Aspects of Corruption In Southeast Asia, in :Arnold J.Heidenheimer, OP.Cit., PP.196-197.

(3)www.abahe.uk.comCameron, S, 1996 , dreaming of a word without Corruption 
قرر الأصفهاني في المفردات بأن الفساد خروج الشيء عن الاعتدال، قليلا كان الخروج أو

كثيرا ويضاده الصلاح ويستعمل ذلك في النفس والبدن (1).

وقد جرى تعريف الفساد بصيغ مختلفة منها انه " اساءة استعمال السلطة العامة لتحقيق مكسب

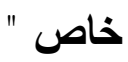

وكذللك يعرف الفساد الإداري بأنه سلوك بيروقراطي منحرف يستهدف تحقيق منافع ذاتيه

بطريقه غير شرعية ويدون وجه حق.

الفساد: هو استخدام المنصب العمومي، لتقتيين مكاسب خاصه ويشمل ذلك الرشوة والابتزاز، وهما

ينطويان بالضرورة على مشاركه طرفين على الاقل ، ويشمل ايضا انواعا اخرى من ارتكاب الاعمال المحظورة التي يستطيع الموظف العام القيام بها بمفرده ومن بينها الاحتيال والاختلاس. كما عرف الفساد على انه إعطاء شىع لشخص يملك سلطة ولكنه يسىء استخدام هذه

السلطة أو القوة في اتجاة مصالح وتفضيلات من يعطيه. (2)

إن شخصا ما فاسد اذا كان هذا الثخص يتمتع بأي سلطه أو نفوذ أو منصب قد أوكل اليه

عن طريق التعيين أو منصب شرفي، ويقوم هذا الثخص باستغلال ما بحوزته من نفوذ أو سلطة أو منصب لتحقيق مصالح شخصية أو مصالح جماعيه لأثخاص اخرين قد طلبوا منه ذلك وهذا

ينطبق على السلوك الفردي والجماعي عموما.(

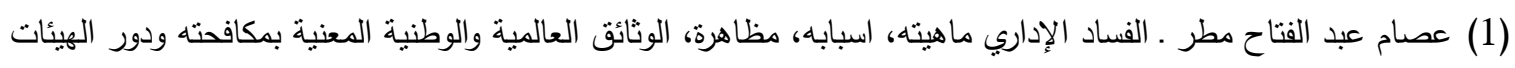

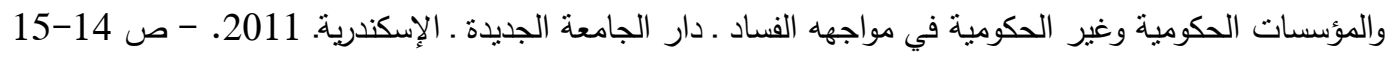

(2)Corruption: A theoretical perspective, http: //Bharast.com./CUC/Corruption. Hot $^{2}$

(3)HK ey , cime ,coercion, corruption and volunta exchange :conceptual issues,$^{3}$

http://ww w .TL. Bangladesh. Org/ docs/ research/ ammo Bibi,Htm 
أن الفساد هو أساءه استعمال السلطة العامة لتحقيق مكسب خاص وكذلك يعرف الفساد الإداري بأنه سلوك بيروقراطي منحرف يستهف تحقيق منافع ذاتيه بطريقه غير شرعيه ويدون وجه حق

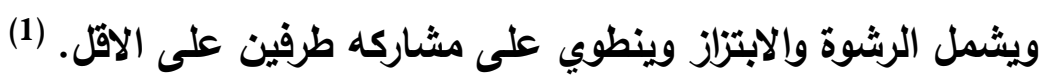
- - كما عرف الفساد على أنه سلوكا منحرفا عن الواجبات والقواعد الرسميه للدور العام (سواء منتخب أو معين) لتحقيق مكاسب شخصيه او عائليه او شلليه وينطبق هذا التعريف مع ما قاله عالم الاجتماع الأمريكي الجنسية "ينتجون" - بأن الفساد هو سلوك الموظف العام الأى ينحرف به عن القواعد القانونية السائدة بهدف تحقيق منفعة ذاتيه (2). ثثانيا : أثثار الفساد على المجال الاقتصادى ـ

(1) يساهم الفساد في تلنى كفاءة الاستثمار العام واضعاف مستوى الجودة في البنية التحتية العامة وذلك بسبب الرشاوى التي تحد من الموارد المخصصة للاستثمار وتسيئ توجيهها او تزيد من تكلقتها.

(2) للفساد إثر مباشر في حجم ونوعيه موارد الاستثمار الأجنبي، ففي الوقت الذي تسعى فيه البلان النامية الى استقطاب موارد الاستثمار الأجنبي لما تنطوي عليه هذه الاستثمارات من امكانات نقل المهارات والتكنولوجيا، فقد اثبتت الدراسات ان الفساد يضعف هذه التدفقات الاستثمارية وقا يعطلها مما يمكن ان يسهم في تدنى انتاجيه الضرائب مما يؤدى الى تراجع مؤشرات التنمية البشرية خاصة فيما يتعلق بمؤشرات التعليم والصحة.

(1) عماد الدين اسماعيل - "طاهرة الفساد الإداري في الاجهزة الحكومية بالتركيز على الرشوة . -كليه الاقتصاد والعلوم السياسية

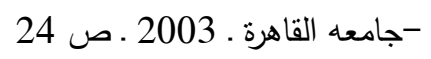

(2)Bendor, 6. Corruption, Institution aviation and Polititicial Development V. 2 ,L, 1,1974,P.641 
(3) يرتبط الفساد بتردي حالة توزيع الاخل والثروة، من خلال استغلال اصحاب النفوذ لمواقعهم المميزة في المجتمع وفى النظام السياسي، مما يتيح لهم الاستثمار بالجاتب الاكبر من المنافع الاقتصادية التي يقدمها النظام بالإضافة الى قراتهم على مراكمه الاصول بصفه مستمرة مما يؤدى الى توسيع الفجوة بين هذه النخبة ويقية افراد المجتمع.

(4) يمكن لظاهرة الفساد ان تنمو وتتزيا بفعل عوامل اجتماعيه ضاريه في بنية وتكوين المجتمعات البشرية ونسق القيم السائدة اذ تلعب العادات والتقاليد الاجتماعية وسريانها دورا في نمو هذه الظاهرة او اقتلاعها من جذورها وهذه العادات والتقاليا مرتبطة ايضا بالعلاقات التقليدية السائدة في المجتمع.

(5) غياب الثقة في تطبيق المثل الانسانية وزعزعه القيم الأخلاقية القائمة على الصدق والامانة والعدل والمساواة وتكافؤ الفرص وتحول هذه القيم الأخلاقية الى جرائم بسبب غياب هذه القيم.

وللفساد له أثثار اخرى على الاقتصاد (1): 1. يعوق النمو الاقتصادي من خلال استخلاص الريع "الاستثمار بالفائض الاقتصادي" مما يؤثر سلبا على هذا النمو سواء بالنسبة لمنظمي المشروعات المحلية أو الأجنبية. 2. يقلل الفساد من الدخل القومي ويبدده من عده نواحي فالفساد في قطاع الضرائب على سبيل المثال يساعد على التهرب من دفع الضرائب المستحقة ويقلل من الحصيلة الضريبية التي عماد الموارد العامه في مصر. 3. البيئة الفاسدة قد تجذب مستثمرين فاسدين يجيدون التعامل مع مثل هذه البيئات فيجنون اضعاف ما يستثمرون ليس على اسس اقتصاديه سليمه بل على اساس استخدامهم لقوى الفساد في المجتمع مما يضر بالاقتصاد الوطني ومصالح المواطنين اسوأ ضرر. 
كما أثثتت بعض الدراســـات إن تأثير الفســاد على النمو الاقتصـــادي كبيرة جداً، اذ تم اختبار مجموعة من المتغيرات لتحليل العلاقة بين الفسـاد وهيكل الإنفاق الحكومي، وأستتتج بأن الفسـاد يخفض الاستثمار والنمو الاقتصادي ويغير من هيكل الإنفاق الحكومي ويؤدي إلى تخفيض معدل

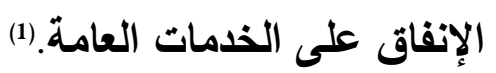

ويصفه عامة يمكن ايجاز بعض الأثار الاقتصادية للفساد (2):

ويوجد أثثار اقتصادية واجتماعية للفساد:

1. يؤثر الفساد على اداء القطاعات الاقتصادية ويضعف النمو الاقتصادي.

2. يؤثر على استقرار وملاءة مناخ الاثر الإيجابي لحوافز الاستثمار بالنسبة للمشاريع المحلية

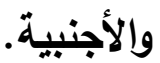

3.يؤدى الفساد الى اضعاف جوده البنية الاساسية والخدمات العامه ويدفع ذوي النفوس الضعيفة للسعي الى الريح غير المشروع عن طريق الرشاوى بلالا من المشاركة في الأنثطة

الإنتاجية.

تأثير الفساد وعبر القتوات المتعددة التي يعمل من خلالها سيكون سلبيا على مسار الاصلاح

الاقتصادي الامر الأى سيقوض من امكانيه تحقيق معدلات مقبولة للنمو تحسين فرص الاستثمار، ففي دراسة اعدها الاقتصادي ( Paolo Mauro) لقياس تأثير الفساد على كل من الاستثمار والنمو لعدد من الدول تتمتع بمستويات مختلفة من الفساد توصل الى ان الدول التي يقل فيها الفساد نسبيا وتفقد ما يقارب 5 \% من نمو ناتجها المحلى الإجمالي سنويا .

( (1)هاني على الطهراوي، النظم السياسية والقانون الدستوري، ط3 الثقافة والنشر والتوزيع، العراق 2008 ص2147-275. (2) فاتن سيد خميس عطية -الفساد المالي والإداري دراسة نظريه تحليلية للأسباب والمظاهر .-- دور الأجهزة الرقابية في مكافحه 


\section{ثالثا: أثار الفساد على حجم وطييعه الايرادات الحكومية.}

أثار الفساد الإداري على حجم وطبيعة الايرادات الحكومية (1):

تخسر الحكومات مبالغ كبيره من الايرادات المستحقة عندما تتم رشوه موظقي الدولة حتى

يتجاهلوا جزء من الانتاج والاخل والواردات في تقويمهم للضرائب المستحقة على هذه النشاطات الاقتصادية، بالإضافة الى ذلك تهر الحكومات كثيرا من مواردها عندما يتم تقديم الدعم الى فئات غير مستحقه ولكنها تتمكن من الحصول عليه رشوه او نقوذ او أي وسيلة اخرى، وهذه الامر يؤثز على الاداء الاقتصادي للاولة.

ويمكن القول بأن الفساد يضر بالأداء الاقتصادي ضررا مؤكدا حيث يشوه عناصر النققات الحكومية كما يضر الفساد على النمو الاقتصادي والثروات والأداء الاقتصادي كما يلاحظ بأن الفساد يضعف من شرعيه الاولة كما يهبط بجوده البيئة الأساسبة والخدمات العامه ويخفض من ايرادات الضرائب كما يؤدى ايضا الى زياده التكاليف السلبية والضارة بشده النمو الاقتصادي كما ان للفساد أثثاره الإيجابية وهو ان يكون مفيد من حيث حمايه النظام السياسي الأى يظهر فيه ويجنيه كما ان للفساد اسبابه الاقتصادية حيث يساهم في تدنى كفاعه الاستثمار العام واضعاف مستوى الجودة في البنيه التحتية كما ان له أثثاره المباشرة في حجم ونوعيه موارد الاستثمار الأجنبي حيث يضعف من استقطاب هذه الموارد كما يرتبط بتردي توزيع الاخل والثروة من خلال استغلال اصحاب التفوذ

لمواقعهم المميزة في المجتمع والنظام السياسي (2)

(1) محمد صادق اسماعيل ، عبد العال الديربى · جرائم الفساد بين آليات المكافحة الوطنية والدولية ـ دراسة قانونية تطبيقيه مقارنه

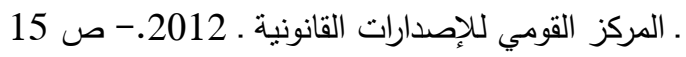
(2)عطيه حسين افندى ـ الإدارة العامه إطار نظرى ـ مداخل للنطوير في قضايا هامه في الممارسة ـ مرجع سابق ص 214 


\section{لريعا: أثثار للفساد على المجال الاجتماعى:}

اما فيما يتعلق بالأضرار الاجتماعية للفساد فهي تنسحب على القضاء وعلى هيبه وسياده القانون وذلك يؤدى بدوره الى انهيار البيئة الاجتماعية والثقافية واتحراف اساليب التعامل وإلحياه بشكل يهدد النسيج الأخلاقي للمجتمع الذى تسود فيه المظالم وانعدام السلوكيات القويمة والتفاوت الكبير في توزيع الاخول الناجم عن تفاوت طبقي كبير (كما في الوقت الحاضر حيث التفاوت في الرواتب لموظفي الدولة) وكذلك يؤدى الفساد الى اختلال التركيبة الاجتماعية ويزيد من الاضطرابات وحالة عدم الاستقرار السياسية الى جانب تعرض شرعيه النظام الديمقراطي والسياسي للتآكل المستمر واخطر ما في الامر هو تركيز الثروة في اجدى حفنه قليلة لتستظلها في غير مصالح

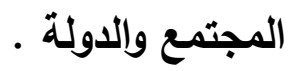

كما يؤدى الفساد الى خلخله القيم الأخلاقية والى الاحباط وانتشار اللامبالاة والسلبية بين افراد المجتمع ويروز التعصب والتطرف في الآراء وانتشار الجريمة كرد فعل لانهيار القيم وعدم تكافؤ الفرص.

كما يؤدى الفساد الى عدم المهنية وفقدان قيمه العمل والتقبل النفسي لفكره التفريط في معايير اداء الواجب الوظيفي والرقابي وتراجع الاهتمام بالحق العام والثعور بالظلم لدى الغالبية.

\section{خامسا: أثثار الفساد على النواحى السباسبة. .}

(1) يؤثر على مدى تمتع النظام بالديمقراطية وقدرته على احترام حقوق المواطنين الأسساسية وفي مقدمتها الحق في المساواة وتكافؤ الفرص، كما يحد من شفافية النظام وإنفتاحه. (2) يؤدي إلى حالة يتم فيها اتخاذ القرارات حتى المصسيرية منها طبقا لمصـالح شــصـية ودون مراعاة للمصالح العامة. 
(3) يقود إلى الصراعات الكبيرة إذا ما تعارضت المصالح بين مجموعات مختلفة . (4) يؤدي إلى ضــف المؤسســات العامة ومؤسسـسـات المجتمع المدني ويعزز دور المؤسـســات التقليدية.

يسـيء إلى ســعة النظام السـياسـي وعلاقاته الخارجية خاصـة مع الدول التي يمكن أن تقدم الدعم المادي لله، ويشــكل يجعل هذه الدول تضــــع شــروطا قد تمس بســيادة الدولة لمنح

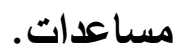

يضعف المشاركة السياسية نتيجة لغياب الثقة بالمؤسسات العامة وأجهزة الرقابة والمساعلة. الفساد يؤثر على المراكز الوظيفية وأدى إلى حدوث موجة من الاضطراب الإداري الذي ينتهي بالخلل إلى جميع أركان الدولة حيث كان كل شخص يتولى منصبه الجيد يسارع لإحاطة نفسه

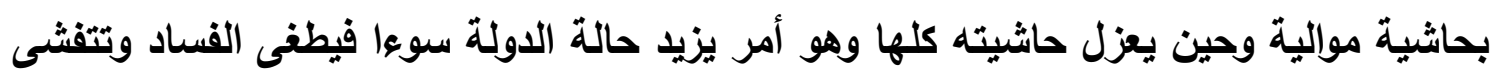

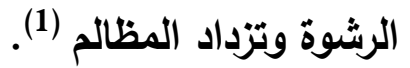

وخلاصه القول في شأن محدات الفساد الإداري في مصر ففي ضوء ما سبق يلاحظ ان الفساد لله أثثاره على النواحي الاقتصادية المتمثلة في تلنى كفاعه الاستثمار كما انه يرتبط بتردي حاله توزيع الدخل والثروة ولم تقتصر أثاره على النواحي الاقتصادية فقط بل تمتد لتثمل التأثير على الايرادات الحكومية حيث تفقد الحكومات مبالغ كبيره نتيجة لانتشار الرشوة والنفوذ كما ان له ايضا أثاره على النمو الاقتصادي والاجتماعي فنجد انه يؤثر على اداء القطاعات الاقتصادية ويحد من قدره الدولة على الحد من الايرادات ويلاحظ ان للفساد أثثاره الاقتصادية المتمثة في تدنى على

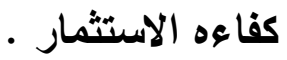
كما يلاحظ ان للفساد الإداري في مصر أثره على النمو الاقتصادي وخفض معدلات الاستثمار ومن ثم خفض الطلب الكلى الذي يؤدى حتما الى تخفيض معدل النمو الاقتصادي ومن ثم فإن الفساد الإداري لا يؤثر فقط على القطاع الاقتصادي بل يمتد ليشمل القطاعات الاخرى. 


\section{الإجراءات السباسبة والحكومية:}

تقويه المؤسسات الحكوميه للسبطرة على الفساد ويمكن تحقيق ذلك على ثلاث محاور هي: (1)تقوية وتدعيم النظم الادارية حتى تتمكن الحكومة من القيام بوجباتها وتقديم خدماتها بكفاعة.

(2)تظوير التثريعات وتنقيتها من القواعد والنصوص التي يستظلها الموظفون في طلب الرشوة والعمولات وتقويه النظام القضائي وتدعيمه بشريا وماديا ليكون قادرا على تحقيق العدالة ومقاومه (الفساد.

(3). زيادة الثفافية وادخال مقاييس جديدة لتقويه دور المجتمع المدني (الجمعيات الأهلية)

$$
\text { القادرة على رقابة الاداء الحكومي. التحس. }
$$

(4) اتباع اساليب اداريه اساسها الجدارة وسياسيه تنافسيه تقوم على عاتق المؤسسات فلا تترك

$$
\text { الامور لمطلق القرارات الفردية. }
$$

(5)رفع مستوى موظف الحكومة المادي والأدبي والمهني ورفع مستوى حسن معامله المواطنين

وتيسير اجراءات تقديم الخدمات وتبسيط الاجراءات وتقليل الخدمات وتبسيط الاجراءات. ـ التأكد من القيم الاخلاقية في اختيار الموظقين المكلفين بأداء الخدمات العامه للمواطنين وخلق بيئة حكومة جيدة الاداء تقلل من الاثر السلبي للفساد على التنمية. الخلاصة: فأن الفساد يعوق النمو الاقتصادي من خلال استخلاص الريع"الاستثمارى بالفائض الاقتصادي " مما يؤثر سلبا على هذا النمو على المشروعات المحلية والأجنبية ويعوق التنمية المستدامة ومعوق لتخفيض الفقر والاداء الحكومي الجيد.

لذا ان أغلب الاراسات الحديثة أثبتت وجود علاقة عكسية بين الفساد والنمو الاتصادي وان هذه العلاقة حتمية في كل الاوقات. 
يرى البحث: أعادة هيكل الأجهزة الإدارية بالدولة، مراجعة القوانين، الفصل في القضايا المرتبطة بالفساد بسرعه حتى ينال المجرم العقاب، تعميق وزيادة شفافية القرارات والممارسات الحكومية، الد من المركزية، خلق جو من الثقة من خلال كافة المستويات الإدارية.

ويصفة عامة لابد من سياسات لمواجهه الفساد على أن تثمل استراتيجيات اقتصاديه وتتموية واجراءات عامة ذات طبيعة ادارية وقانونية للوقاية من الفساد.

ويمكن القول بأن الفساد يضر بالأداء الاقتصادي ضرا مؤكدا حيث يثوه عناصر النفقات الحكومية

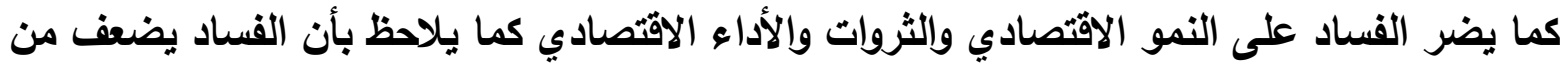
شرعيه الدولة كما يهبط بجوده البيئة الأساسية والخدمات العامه ويخفض من ايرادات الضرائب كما يؤدى ايضا الى زياده التكاليف السلبية والضارة بثده النمو الأتصادي كما ان للفساد أثاره الإيجابية وهو ان يكون مفيد من حيث حمايه النظام السياسي الذى يظهر فيه ويجنيه كما ان للفساد اسبابه الاقتصادية حيث يساهم في تندى كفاءه الاستثمار العام واضعاف مستوى الجودة في البنيه التحتية كما ان له أثاره المباشرة في حجم ونوعيه موارد الاستثمار أولا: نتائج البحث: أثثار الفساد على المجال الاقتصادى: (1) يساهم الفساد في تنىى كفاءة الاستثمار العام واضعاف مستوى الجودة في البنية التحتية العامة وذلك بسبب الرثاوى التي تحد من الموارد الدخصة للاستثمار وتسيئ توجيهها او تزيد من تكلفتها. (2) للفساد إثر مباشر في حجم ونوعيه موارد الاستثمار الأجنبي، ففي الوقت الذي تسعى فيه البلان النامية الى استقطاب موارد الاستثمار الأجنبي لما تتطوي عليه هذه الاستثمارات من امكانات

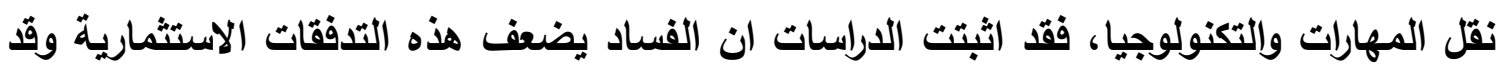


يعطلها مما يمكن ان يسهم في تدنى انتاجيه الضرائب مما يؤدى الى تراجع مؤشرات التنمية البشرية خاصة فيما يتعلق بمؤشرات التعليم والصحة. (3) يرتبط الفساد بتردي حالة توزيع الاخل والثروة، من خلال استغلال اصحاب النفوذ لمواقعهم المميزة في المجتمع وفى النظام السياسي، مما يتيح لهم الاستثمار بالجانب الاكبر من المنافع الاقتصادية التي يقدمها النظام بالإضافة الى قراتهم على مراكمه الاصول بصفه مستمرة مما يؤدى الى توسيع الفجوة بين هذه النخبة ويقية افراد المجتمع.

(4) يعوق النمو الاقتصادي من خلال استخلاص الريع "الاستثمار بالفائض الاقتصادي" مما يؤثر سلبا على هذا النمو سواء بالنسبة لمنظمي المشروعات المحلية أو الأجنبية. (5) يقلل الفساد من الدخل القومي ويبدده من عده نواحي فالفساد في قطاع الضرائب على سبيل المثال يساعد على التهرب من دفع الضرائب المستحقة ويقلل من الحصيلة الضريبية التي عماد الموارد العامه في مصر.

(6) البيئة الفاسدة قد تجذب مستثمرين فاسدين يجيدون التعامل مع مثل هذه البيئات فيجنون اضعاف ما يستثمرون ليس على اسس اقتصاديه سليمه بل على اساس استخدامهم لقوى الفساد في المجتمع مما يضر بالاتتصاد الوطني ومصالح المواطنين اسوأ ضرر. اثثار الفساد على النواحى الاجتماعية :

يؤدى على القضاء على هيبه وسياده القانون وذلك يؤدى بدوره الى انهيار البيئة الاجتماعية والثثافية وإنحراف اساليب التعامل والحياه بشكل يهدد النسيج الأخلاقي للمجتمع . يسود فيه المظالم وانعدام السلوكيات القويمة والتفاوت الكبير في توزيع الدخول الناجم عن تفاوت طبقي كبير (كما في الوقت الحاضر حيث التفاوت في الرواتب لموظقي الدولة. يؤدى الفساد الى اختلال التركيبة الاجتماعية ويزيد من الاضطرابات وحالة عدم الاستقرار 
تعرض شرعيه النظام الديمقراطي والسياسي للتآكل المستمر واخطر ما في الامر هو تركيز

الثروة في أيدى حفنه قليلة لتستظها في غير مصالح المجتمع والدولة .

يؤدى الفساد الى خلخله القيم الأخلاقية والى الاحباط وإنتشار اللامبالاة والسلبية بين افراد

المجتمع وعدم تكافؤ الفرص.

بعض الالبات والسباسات والاجراءات التي بمكن اتباعها للحد من الفساد الإداري (1)

(1)(اصلاح النظام المصرفي والسيطرة عليه لمنع سارقى المال العام من الاختباء وإلتخفى فيه.

(2)تكوين مؤسسات رقابية مستقله تشرف على مراقبه العمل في الهيئات الحكومية والخاصة

في حد سواء.

(3)الحد من البيروقراطيه المعقدة الروتين والحد من وضع العراقيل امام مصالح الناس.

(4) تظوير القواعد النظامية المطبقة.

(5) اشعار الموظف العام بالمسؤولية الملقاة عليه.

(6)تفعيل دور التدريب العملي لكي يؤدى دوره في توجيه الموظف الى سبل اكتساب الاخلاقيات

الادارية الحميدة والالتزام بها سلوكيا ومهنيا.

كيفية مواجهة الفساد على المستوى المحلى في مصر : (2)

أ- وضع حد اقصى لبقاء رئيس المدينة والمركز في منصبه في المدينة الواحدة ويحيث

لا تلا يتجاوز ثلاث سنوات.

(1) شحاته ابو زيد شحاته - سرطان الفساد المالي والإداري - مؤتمر دور الاجهزة الرقابية في مكافحة الفساد المالي والإداري

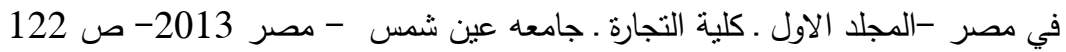

(2) اكرام بدر الدين -اللامركزية والكفاءة الادارية ومكافحة الفساد -كليه الاقتصاد والعلوم السياسية .-جامعه القاهرة.. 2006 - 
ب- - تلعيم سلطة المجالس المحلية في مختلف مستوياتها ازاء الاجهزة التنفيذية الموازية لها.

ج- تدعيم اللامركزية من خلال نقل كافة سلطات واختصاصات الوزارات التي تدخل في إطار الادارة المحلية الى المستوى المحلى.

د- زيادة دور مؤسسات المجتمع المدني والمنظمات الثعبية في نشاط الادارة المحلية

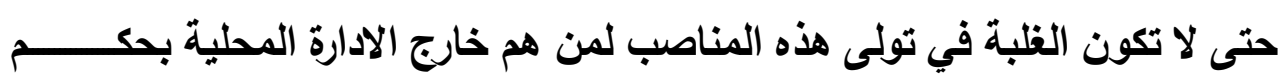
عملهم الأصلي (ضباط مستشارين الخ).

هـ - استحداث الاجهزة الرقابية المسئولة عن مكافحه الفساد حال ظهوره مع زيادة تفعيل مشاركه المواطنين على المستويات المحلية مما يشكل نوعا من الرقابة الثعبية على الفساد يساعد على المراجعة والاصلاح لما يحدث من تجاوزات.

ففي ضوء ما سبق يلاحظ ان الفساد له أثثاره على النواحي الاقتصادية المتمثلة في تدنى كفاعه الاستثمار كما انه يرتبط بتردي حاله توزيع الدخل والثروة ولم تقتصر أثثاره على النواحي الاقتصادية فقط بل تمتد لتشمل التأثير على الايرادات الحكومية حيث تفقد الحكومات مبالغ كبيره نتيجة لانتثار الرشوة والنفوذ كما ان له ايضا أثاره على النمو الاقتصادي والاجتماعي فنجد انه يؤثر على اداء القطاعات الاقتصادية ويحد من قدره الدولة على الحد من الايرادات ويلاحظ ان للفساد أثاره الاقتصادية المتمثلة في تلنى على كفاعه الاستثمار •

كما يلاحظ ان للفساد الإداري في مصر أثره على النمو الاثتصادي وخفض معدلات الاستثمار ومن ثم خفض الطلب الكلى الأي يؤدى حتما الى تخفيض معدل النمو الاقتصادي ومن ثم فِان الفساد الإداري لا يؤثر فقط على القطاع الاقتصادي بل يمتد ليشمل القطاعات الاخرى. 
الخلاصة: فأن الفساد يعوق النمو الاقتصادي من خلال استخلاص الريع"الاستثمارى بالفائض الاقتصادي " مما يؤثر سلبا على هذا النمو على المشروعات المحلية والأجنبية ويعوق التنمية المستدامة ومعوق لتخفيض الفقر والاداء الحكومي الجيد.

يرى البحث : أعادة هيكل الأجهزة الإدارية بالدولة، مراجعة القوانين، الفصل في القضايا المرتبطة بالفساد بسرعه حتى ينال المجرم العقاب، تعميق وزيادة شفافية القرارات والممارسات الحكومية، الدد من المركزية، خلق جو من الثقة من خلال كافة المستويات الإدارية.

ويصفة عامة لابد من سياسات لمواجهه الفساد على أن تثمل استراتيجيات اقتصاديه وتتموية واجراءات عامة ذات طبيعة ادارية وقانونية للوقاية من الفساد.

ثنانيا: التوصيات

ووفقا للهاف من البحث وما انتهى اليه من نتائج يوصى البحث بما يلي: 1 ـ تعزيز الثفافية في عمليات اتخاذ القرار وتثجيع اسهام الناس فيها. 2

3 4 اعادة هيكله المؤسسات الحكومية بالكامل وتغير نظام الادارة بها ويقوم الجهاز المركزي للتنظيم

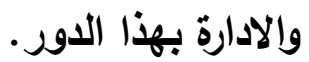
5 5 التركيز على الاور الرقابي وعدم القائه على عاتق فرد واحد في المكان او الهيئة بأسرها وانما بث روح الفريق في جميع العاملين بالمؤسسات او الهيئة الحكومية. 6 7 التركيز على الوازع الديني والترهيب من الوقوع في الرشوة والفساد الإداري والترغيب في اكتساب المال من العمل الحلال الخالص. 
8 استحداث اقسام اداره وتنميه الموارد البشرية في جميع المؤسسات والهيئات الحكومية للعناية بحاله العاملين المهنية والنفسية والاجتماعية وتتابع مستمر للمتقلم والمتقاعس منهم وتطبيق مبدأ الثواب والعقاب.

9 تفعيل دور التدريب لكي يؤدى دوره في توجيه الموظف لاكتساب الاخلاقيات الإدارية الحميدة والالتزام بها سلوكيا ومهنيه وتنميه مهاراته القنية. 10 وضع انظمه وقوانين صارمده لمعاقبه المتورطين في قضايا فساد. 11 11 انشاء لجنه عليا مستقله للتحقيق في التجاوزات والشكاوى المتعلقة بقضايا الفساد. 12 تقويه الرقابة الإدارية واحكامها لتقوم بمعالجه الانحراف وسرعه البت في المخالفات. 


\section{قائمة مراجع البحث}

أولا : المراجع العربية :

1. اكرام بلر الاين -اللامركزية وإلكفاءة الادارية ومكافحة الفساد -كليه الاقتصاد والعلوم السياسية -

2. عطية حسين أفندي ـ الادارة العامة ـ إطار نظري ـ مداخل للتطوير ـ وقضايا هامة في الممارسة ـ

دار النهضة العربية ـ كليه الاقتصاد والعلوم السياسية ـ جامعة القاهرة 2002 ـ

3. عطية حسين أفندي ـ الادارة العامة ـ إطار نظري ـ مداخل للتطوير ـ وقضايا هامة في الممارسة ـ دار النهضة العربية ـ كليه الاقتصاد والعلوم السياسية ـ جامعة القاهرة 2002

4. عصام عبد الفتاح مطر ـ الفساد الإداري ماهيته، اسبابه، مظاهرة، الوثائق العالمية والوطنية المعنية بمكافحته ودور الهيئات والمؤسسات الحكومية وغير الحكومية في مواجهه الفساد ـ دار الجامعة الجديدة ـ الإسكندرية. 2011.

5. عماد الدين اسماعيل ـ ظاهرة الفساد الإداري في الاجهزة الحكومية بالتركيز على الرشوة ـ كليه الاقتصاد والعلوم السياسية ـ جامعه القاهرة 2003.

6. محمد صادق إسماعيل: جرائم الفساد بين آليات المكافحة الوطنية والدولية دراسة قانونية تطبيقية مقارنة ،المركز القومى للاصدارات القانونية ، القاهرة ، 2012. 7. قصي الحسين، الفساد والسلطة، بيروت، المؤسسة الجامعية للارسات والنشر . 1997. 


\section{ثانيا: مصادر اخرى:}

1. فاتن سيد خمس عطية ـ مراقب حسابات (أ) بالجهاز المركزي للمحاسبات ـ الفساد المالي والإداري دراسة نظريه تحليله للأسباب والمظاهر ـ دور الاجهزة الرقابية في مكافحه الفساد المالي والإداري في مصر . مؤتمر دور الاجهزة الرقابية في مكافحة الفساد المالي والإداري في مصر .. جامعه

$$
\text { عين شمس - جزء (2) - } 2013
$$

2. ساهر عبد الكريم مهذى، الفساد الإداري، أسبابه وأثاره وأهم أساليب المعالجة ـ شبكه المعلومات

$$
\text { الاولية. }
$$

3. هاني على الطهراوي، النظم السياسية والثانون الدستوري، ط3 الثقافة والنشر والتوزيع، العرلق

4. شحاته ابو زيد شحاته - سرطان الفساد المالي والإداري - مؤتمر دور الاجهزة الرقابية في مكافحة الفساد المالي والإداري في مصر -المجلد الاول ـ كلية التجارة . جامعه عين شمس - مصر 


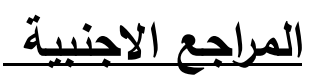

I- Books :

(1)W.F.Wertheim, Sociological Aspects of Corruption In Southeast Asia, in :Arnold J.Heidenheimer, OP.Cit., PP.196-197.

(2)Bendor, 6. Corruption, Institution aviation and Polititicial Development V. ,L,1,1974,P.641

$\underline{\text { II - Sides of Internet : }}$

(1)www.abahe.uk.comCameron, S, 1996 , dreaming of a word without

(2)Corruption "Macleans , pp. 36-37

Corruption: A theoretical perspective, http:

(3) //Bharast.com./CUC/Corruption. Hot

(4)HK ey , cime ,coercion, corruption and volunta exchange :conceptual (issues ,

(5)http://ww w .TL. Bangladesh. Org/ docs/ research/ ammo Bibi,Htm

(6)HK ey , cime ,coercion, corruption and volunta exchange :conceptual (issues ,

(7) http://ww w .TL. Bangladesh. Org/ docs/ research/ ammo Bibi,Htm 